\title{
GMR
}

\section{Study on quality standards for Chimonanthus nitens}

\author{
B. Zhou, S.-Z. Liu, M.-J. Li, Z.-H. Chen, P. Wang and D. Cheng \\ School of Pharmacy, Jiangxi Science and Technology Normal University, \\ Nanchang, China
}

Corresponding author: B. Zhou

E-mail: tju_zhoubin@163.com

Genet. Mol. Res. 15 (3): gmr.15038984

Received July 21, 2016

Accepted August 1, 2016

Published August 29, 2016

DOI http://dx.doi.org/10.4238/gmr.15038984

Copyright $(C 2016$ The Authors. This is an open-access article distributed under the terms of the Creative Commons Attribution ShareAlike (CC BY-SA) 4.0 License.

\begin{abstract}
Chimonanthus nitens Oliv. is a commonly used traditional Chinese medicine. Terpenoids, flavonoids, and coumarins are usually considered its main bioactive ingredients. Thus, qualitative and quantitative analyses of these compounds are crucial in quality control studies of Chimonanthus nitens. In this study, five compounds were identified by double-development thin layer chromatography (TLC) and the content of four compounds was determined by high performance liquid chromatography; the detection wavelength was set to $344 \mathrm{~nm}$ and the column temperature was $40^{\circ} \mathrm{C}$. All calibration curves showed good linear regression $\left(R^{2}>0.9995\right)$. The average recoveries ranged from 97.06 to $104.44 \%$. The RSD was below $4.2 \%$. Four compounds remained stable over $24 \mathrm{~h}$ and the relative standard deviation (RSD) of the precision of their measurement was less than $1.5 \%$. The developed method was reproducible, sensitive, and simple, and could be used for quality control of Chimonanthus nitens.
\end{abstract}

Key words: Chimonanthus nitens; TLC; HPLC; Scopoletin; Scoparone

Genetics and Molecular Research 15 (3): gmr.15038984 


\section{INTRODUCTION}

Chimonanthus nitens (family Calycanthaceae), a specific genus in China, has been used to treat colds and influenza for centuries. It is mainly found in Dexing, Wuyuan of Jiangxi province and Huizhou in the Anhui province. Previous studies have reported that the dry leaf extract shows obvious bioactivities, including cough relief, and anti-inflammatory, antipyretic, and anti-bacterial properties (Diao et al., 2002; Li and Shu, 2009). C. nitens is rich in volatile oils (Zhan and Xu, 2006; Xu et al., 2006), alkaloids, flavonoids, and coumarins (Xiao et al., 2005; Sun et al., 2009; Shu et al., 2010). Currently, quality control analysis of C. nitens is an area of research still undergoing investigation (Li et al., 2010).

Since the polarity of different compounds varies due to the diversity of their molecular structures, simultaneous analysis by one method is difficult. Thin layer chromatography (TLC) is usually used for qualitative analysis and high performance liquid chromatography (HPLC) is used to determine the contents of different components. In order to improve the quality of this kind of herb, double-development high performance thin layer chromatography (HPTLC) was used to identify three terpenoids (cineole, $\beta$-caryophyllene, linalool) and two coumarins (scopoletin, scoparone) in this study. HPLC was used to determine the contents of four kinds of compounds; three coumarins (scopoletin, isofraxidin, coparone) and one flavonoid (rutin). The developed method could be applied to quality control of this herb.

\section{MATERIAL AND METHODS}

\section{Chemicals and materials}

Linalool, $\beta$-caryophyllene, and cineole were obtained from International Laboratory (Lexington, USA). Scopoletin and isofraxidin were purchased from Yuanye Biological Technology Co., Ltd. (Shanghai, China), and scoparone and rutin were isolated and identified in our laboratory. C. nitens was bought from Wuyuan (Jiangxi, China). They were identified by associate Professor ke-zong Deng (Jiangxi University of Traditional Chinese Medicine). Double distilled water was prepared using a Millipore Milli Q-Plus system (Millipore, Billerica, MA, USA). Acetonitrile and methanol were bought from Uni-Chem (Belgrade, Serbia and Montenegro).

\section{Instrumentation}

HPLC analysis was carried out on an Agilent HPLC instrument (Agilent Technologies, USA) equipped with a G1312A dual pump, G1332A online degasser, G1316A column temperature controller, G1313A automatic injector, G1315B diode array detector, and Agilent Technologies ChemStation software. The analytical column was an Eliter Hypersil ODS 2 column ( 250 x 4.6 $\mathrm{mm}, 5 \mu \mathrm{m})$ along with an Agilent $\mathrm{C}_{18}$ guard column (12.5 x $4.6 \mathrm{~mm}$ I.D., $\left.5 \mu \mathrm{m}\right)$.

\section{Chromatography}

The mobile phase consisted of water (A) and acetonitrile (B), and the flow rate was 1 $\mathrm{mL} / \mathrm{min}$. The following gradient elution program was adopted: $12 \% \mathrm{~B}$ between $0-26 \mathrm{~min}, 12$ to $13.5 \%$ B between $26-28 \mathrm{~min}$, held at $13.5 \%$ B from $28-40 \mathrm{~min}, 13.5$ to $12 \%$ B during $40-$

Genetics and Molecular Research 15 (3): gmr.15038984 
$45 \mathrm{~min}$, and held at $12 \%$ B between $45-60$ min. The injection volume was $10 \mu \mathrm{L}$, the column temperature was $40^{\circ} \mathrm{C}$, and $344 \mathrm{~nm}$ was used as the detection wavelength.

Samples and standards were spotted on silica gel plates. The width of the spots was $7 \mathrm{~mm}$ and the space between two spots was $8 \mathrm{~mm}$. The migration distance was $50 \mathrm{~mm}$ with chloroform and methanol $(9: 1, \mathrm{v} / \mathrm{v})$. After development, the plate was dried by a blower and migrated to 100 $\mathrm{mm}$ with a mixture of petroleum ether and ethyl acetate (10:1). The plate was viewed under 365 $\mathrm{nm}$ light, then colorized with $1 \%$ vanillin $-\mathrm{H}_{2} \mathrm{SO}_{4}$ solution and warmed at $110^{\circ} \mathrm{C}$.

\section{Standard preparation}

For HPLC, stock solutions of scopoletin $(1.133 \mathrm{mg} / \mathrm{mL})$, isofraxidin $(1.013 \mathrm{mg} / \mathrm{mL})$, rutin $(1.502 \mathrm{mg} / \mathrm{mL})$, and scoparone $(1.222 \mathrm{mg} / \mathrm{mL})$ were prepared by dissolving definite amounts of reference compounds in methanol. Blended reference solutions were prepared by mixing the stock solutions with methanol; the concentrations of the four components were $56.65,24.312,90.12$, and $24.44 \mu \mathrm{g} / \mathrm{mL}$, respectively. Working solutions $(1,2,4,6$, and $8 \mathrm{~mL})$ were diluted to $10 \mathrm{~mL}$ with methanol to obtain calibration standards. The standard solutions were filtered through a $0.45 \mu \mathrm{m}$ membrane filter and then injected into the HPLC system.

For HPTLC, stock solutions of cineole, $\beta$-caryophyllene, linalool, scopoletin, and scoparone were obtained by adding $2 \mathrm{~mL}$ methanol to accurately weighed amounts of standard compounds.

\section{Sample preparation}

For HPLC, samples (40 meshes, $1.0 \mathrm{~g}$ ) were accurately weighed into a $100 \mathrm{~mL}$ triangular flask and ultrasonically extracted once $(1 \mathrm{~h})$ with $25 \mathrm{~mL}$ methanol. The extracts were filtered through a $0.45 \mu \mathrm{m}$ membrane, and then $10 \mu \mathrm{L}$ was injected into the instrument.

For HPTLC, the sample ( 40 mesh, $0.5 \mathrm{~g}$ ) was accurately weighed into a test tube and $5 \mathrm{~mL}$ methanol was added. After the sample had been mixed for approximately $30 \mathrm{~s}$, it was ultrasonically extracted $(881 \mathrm{~W}, 43 \mathrm{kHz})$ for $60 \mathrm{~min}$ at room temperature $\left(25^{\circ} \pm 2^{\circ} \mathrm{C}\right)$. The extracts of samples were centrifuged at $3500 \mathrm{rpm}$ for $10 \mathrm{~min}$ and the supernatant was then placed into a tube for analysis.

\section{Method validation}

The proposed method for HPLC analysis was validated according to linearity, precision, stability, repeatability, and recovery. The precision was evaluated by determining the concentration of reference solutions six times within one day. Repeatability was measured by determined the contents of analytes in six individual samples solutions. To evaluate stability, the peak areas of reference compounds were measured every $2 \mathrm{~h}$ during one day. The precision, repeatability, and stability are expressed by the relative standard deviation (RSD). The accuracy of the method was assessed by determining sample recovery.

\section{RESULTS}

\section{Chromatography}

The optimized developing systems were as follows: chloroform and methanol (9:1)

Genetics and Molecular Research 15 (3): gmr.15038984 
were used for the first development to separate high-polarity compounds scopoletin and scoparone, and a mixture of ethyl acetate and petroleum ether (1:10) was used for the second run to separate linalool, $\beta$-caryophyllene, and cineole. TLC identification was highly specific and the spots were clearly separated. Chromatograph charts shown in Figure 1.

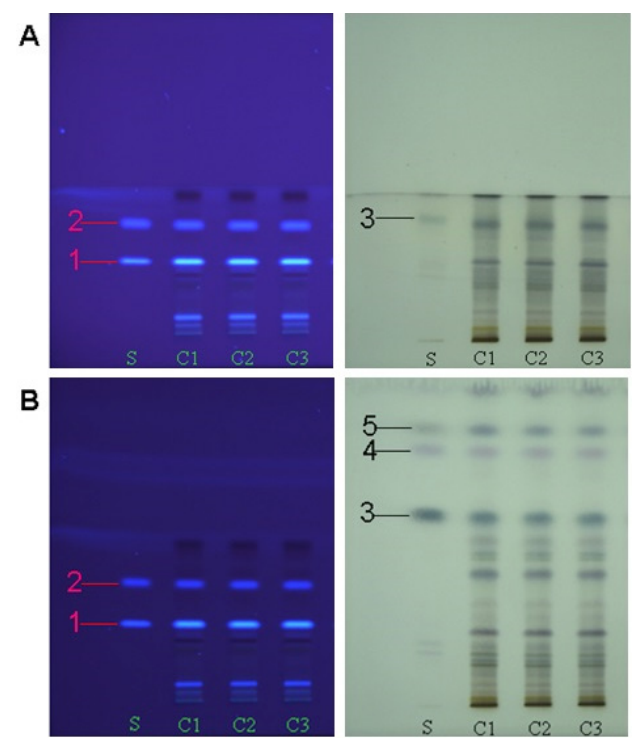

Figure 1. TLC results of reference substances and samples for (A) first and (B) second runs on plates observed at $\lambda$ $=365 \mathrm{~nm}$ (left) and colorized with $1 \%$ vanillin- $\mathrm{H}_{2} \mathrm{SO}_{4}$ solution (right). $\mathrm{S}$ is the mixed reference substance and $\mathrm{C} 1-$ C3 are three batches of samples. 1. Scopoletin. 2. Scoparone. 3. Linalool. 4. $\beta$-caryophyllene. 5. Cineole.

The developed HPLC method was set up and validated. It could determine simultaneously the content of four bioactive components in Chimonanthus nitens. Different proportions of methanol, acetonitrile, and water were tested and comparison showed that all of the analytes were separated with good resolution using the acetonitrile-water system and a wavelength of $344 \mathrm{~nm}$. Typical HPLC chromatograms of standards and samples of Chimonanthus nitens are shown in Figure 2. They show that the peaks of different components in Chimonanthus nitens did not interfere with each other.
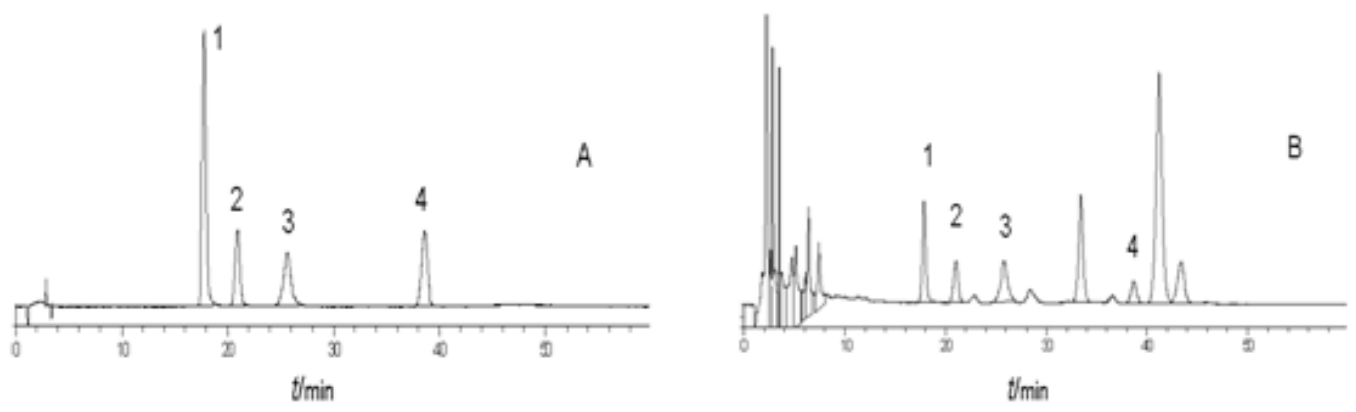

Figure 2. HPLC chromatograms of standards (A) and samples of Chimonanthus nitens (B). 1. Scopoletin. 2. Isofraxidin. 3. Rutin. 4. Scoparone. 


\section{Method validation}

The calibration curves had good linearity for each analyte $(R>0.9992)$. Precision, stability, and repeatability were measured for these compounds (Table 1). The RSD of both precision and repeatability for the four compounds was below $2.50 \%$. The sample solutions were stable over $24 \mathrm{~h}$. All recoveries for the four compounds were between 97.66-104.44\% (Table 1).

Table 1. Results for the four compounds tested in Chimonanthus nitens.
\begin{tabular}{l|c|c|c|c|c|c|c}
\hline Analyte & \multicolumn{2}{|c|}{ Regression } & $\begin{array}{c}\text { Precision } \\
(\mathrm{RSD}, \%)\end{array}$ & $\begin{array}{c}\text { Stability } \\
\text { RSD }(\%)\end{array}$ & $\begin{array}{c}\text { Repeatability } \\
\text { RSD }(\%)\end{array}$ & $\begin{array}{c}\text { Detection recovery } \\
(\mathrm{RSD} \%, \mathrm{~N}=6)\end{array}$ \\
\cline { 2 - 7 } & $\begin{array}{c}\text { Linear regression } \\
\text { equation } \\
(\mathrm{y}=\mathrm{ax}+\mathrm{b})\end{array}$ & $\mathrm{R}$ & $\begin{array}{c}\text { Linear range } \\
(\mu \mathrm{g} / \mathrm{mL})\end{array}$ & & & & \\
\hline Scopoletin & $\mathrm{y}=21.111 \mathrm{x}-5.20$ & 0.9999 & $5.665-56.65$ & $0.26 \%$ & $2.60 \%$ & $0.86 \%$ & $97.06(1.62)$ \\
\hline Isofraxidin & $\mathrm{y}=16.375 \mathrm{x}-0.4160$ & 0.9999 & $2.4312-24.312$ & $0.64 \%$ & $1.88 \%$ & $0.88 \%$ & $102.86(0.93)$ \\
\hline Rutin & $\mathrm{y}=3.2261 \mathrm{x}-14.052$ & 0.9992 & $2.444-24.44$ & $1.48 \%$ & $2.66 \%$ & $1.53 \%$ & $104.44(4.2)$ \\
\hline Scoparone & $\mathrm{y}=20.218 \mathrm{x}-0.3280$ & 0.9999 & $9.012-90.12$ & $0.33 \%$ & $1.65 \%$ & $2.21 \%$ & $102.18(1.81)$ \\
\hline
\end{tabular}

\section{Application}

Chimonanthus nitens is a classic herb that is well used in China. In the study, we established a fast and accurate method that can simultaneously analyze the content of four major active components in Chimonanthus nitens. The results are shown in Table 2.

Table 2. Contents of four components in samples of Chimonanthus nitens.

\begin{tabular}{l|c|c|c|c|c|c|c}
\hline & \multicolumn{7}{|c}{ Contents of Analyte $(\mu \mathrm{g} / \mathrm{g})$} \\
\hline Analyte & 1 & 2 & 3 & 4 & 5 & Average Content & RSD (\%) \\
\hline Scopoletin & 264.83 & 263.79 & 267.12 & 262.42 & 261.68 & 263.97 & 0.81 \\
\hline Isofraxidin & 162.95 & 161.42 & 162.97 & 163.06 & 160.23 & 162.13 & 0.78 \\
\hline Rutin & 849.88 & 855.8 & 864.13 & 837.23 & 838.85 & 849.18 & 1.34 \\
\hline Scoparone & 88.49 & 87.29 & 87.45 & 91.35 & 88.75 & 88.67 & 1.84 \\
\hline
\end{tabular}

\section{DISCUSSION}

For optimization, different proportions of ethyl acetate, formic acid, and water (8:1:1, 7:1.5:1.5), ethyl acetate and methanol $(7: 3,8: 2)$, and petroleum ether and ethyl acetate $(9: 1,10: 1,15: 1)$ were studied. Due to the differences in polarity, it is difficult to separate the components in one development. Thus, double-development was adopted. Since the polarity of different compounds vary, it is very difficult to separate them well using isocratic elution. Experimental conditions such as the mobile phase and wavelength were optimized to obtain good separation.

Terpenoids are the main effective components of volatile oil, and flavonoids and coumarins have definite pharmacological effects in the natural plant (Yi, 2012; Kong et al., 2012). Thus, qualitative and quantitative analyses of these compounds in traditional Chinese medicine are of great importance. This developed method has good reproducibility, is sensitive and simple, and could be used for quality control of $C$. nitens. In the future, further development of a TLC method for qualitative analysis of flavonoids and a HPLC method for quantitative analysis of terpenoids will be required.

Genetics and Molecular Research 15 (3): gmr.15038984 


\section{Conflicts of interest}

The authors declare no conflict of interest.

\section{ACKNOWLEDGMENTS}

Research supported by the project from the National Natural Science Foundation of China (grant \#81560635 to Bin Zhou).

\section{REFERENCES}

Diao JC, Wu XZ and Ding G (2002). Experimental study on disinfection and antibacterial of Chimonanthus nitens Oliv. Jiangxi J. Trad. Chin. Med. 33: 35.

Kong LL, Hu JF and Chen NH (2012). Chin. Pharmacol. Bull. 28: 165-169.

Li SS and Shu RG (2009). Research progress on chemical composition and pharmacological effects of Chimonanthus nitens. West China J. Pharm. Sci. 24: 198-200.

Li YG, Lu JZ, Chen J, Shu RG, et al. (2010). Study on quality standards of authentic ingredients of Chimonanthus nitens Oliv from Jiangxi. Chin. Tradit. Herbal Drugs 41: 836-839.

Shu RG, Li SS, Hu HW and Zhang PZ (2010). Studies on chemical constituents of Chimonanthus nitens. J. Chin. Pharm. Sci. 45: 1134-1135.

Sun LR, He MZ, Feng YL, Chen KP, et al. (2009). Studies on chemical constituents of Chimonanthus nitens Oliv. Chin. Tradit. Herbal Drugs 40: 1214-1216.

Xiao BK, Liu YM, Feng SX, Huang RQ, et al. (2005). Studies on chemical constituents of Chimonanthus nitens Oliv(I). Chin. Tradit. Herbal Drugs 36: 187-189.

Xu NJ, Bai HB, Yan XJ, Xu JL, et al. (2006). Analysis of volatile components in essential oil of Chimonanthus nitens by Capillary Gas Chromatography-Mass Spectrometry. J. Instrumental Analysis 25: 90-93.

Yi WS (2012). Research progress of flavonoids biological activity. Guang Zhou Chem. Industry 40: 47-50.

Zhan ZG and Xu C (2006). GC/MS studies on chemical composition of the essential oil of Chimonanthus nitens Oliv. Chin. J. Pharm. Analysis 26: 1168-1170. 